\title{
Human leukocyte antigen class I and class II alleles are associated with susceptibility and resistance in borderline leprosy patients from Southeast Brazil
}

Fabiana Covolo de Souza-Santana ${ }^{1 *}$, Elaine Valim Camarinha Marcos', Maria Esther Salles Nogueira², Somei Ura ${ }^{3}$ and Jane Tomimori ${ }^{4}$

\begin{abstract}
Background: Evidence suggests that human leukocyte antigen (HLA) alleles influence the host immune response against Mycobacterium leprae. However, the association between HLA alleles and borderline (B) leprosy has not been studied. The aim of this study was to determine whether HLA class I and II molecules are associated with susceptibility or resistance to B leprosy including borderline-tuberculoid (BT), borderline-borderline (BB), and borderline-lepromatous (BL).

Methods: DNA was obtained by the salting-out technique from the blood samples of 202 patients with $B$ leprosy and 478 control subjects. HLA class I ( $A^{*}, B^{*}$, and $C^{*}$ loci) and class II (DRB1* and DQB1* loci) genotypes were determined by polymerase chain reaction amplification and reverse hybridization with sequence-specific oligonucleotide probes and sequence-specific primers.

Results: The case-controlled analysis results showed a significant association between B leprosy and HLA-C*05 (5.94\% vs. $14.02 \% ; p=0.002, \mathrm{OR}=0.38,95 \% \mathrm{Cl}=0.20-0.73, p c=0.032$ ) and $\mathrm{HLA}-\mathrm{DRB}{ }^{*} 07$ (16.34\% vs. $26.77 \%$; $p=0.003, \mathrm{OR}=0.53,95 \% \mathrm{Cl}=0.3-0.8, p c=0.039$ ). A protective association was observed between $\mathrm{BL}$ leprosy and HLA-DQB1 ${ }^{* 02}(18.18 \%$ vs. 39.53\%; $p=0.005, \mathrm{OR}=0.34,95 \% \mathrm{Cl}=0.15-0.75, p c=0.025)$. In reactional patients, a significant association was observed between HLA-B*15 (28.72\% vs. $12.76 \% ; p=0.011, \mathrm{OR}=2.75,95 \% \mathrm{Cl}=1.30-5.85$, $p C=0.352)$ and predisposition to reversal reaction. Haplotype analysis showed that $A^{*} 02-B^{*} 07-C * 07-D R B 1 * 15-D Q B 1 * 06$ (2.97\% vs. $1.04 \% ; p=0.015)$ and $A^{*} 02-B^{*} 40-C^{*} 03-D R B 1 * 13-D Q B 1 * 06(1.73 \%$ vs. $0.10 \% ; p=0.0011)$ were associated with susceptibility to the $B$ form. The presence of the HLA-DRB ${ }^{*} 02$ or HLA-DRB $1 * 03 / H L A-D Q B 1{ }^{*} 01$ haplotypes in $B$ patients (22.05\% vs. 33.0\%; $p=0.005$ ) suggested the involvement of these haplotypes in this clinical form of the disease.
\end{abstract}

Conclusions: The results indicate the involvement of HLA class I and class II molecules in B leprosy and reversal reactions; it also suggest a role for HLA in polarization of the disease in this group of patients.

Keywords: Leprosy, Borderline, HLA alleles, Genetics, Mycobacterium leprae

\footnotetext{
*Correspondence: fsouza@ilsl.br

${ }^{1}$ Immunogenetics Laboratory, Instituto Lauro de Souza Lima, Rod. Cte João Ribeiro de Barros, km 225/26, Bauru, SP CEP: 17039-800, Brazil

Full list of author information is available at the end of the article
} 


\section{Background}

Leprosy is a chronic infectious disease caused by Mycobacterium leprae, an obligate intracellular pathogen that has a preference for Schwann cells in the peripheral nervous system and macrophages in the skin. The host cellular immune response is the main mechanism of resistance to the parasite [1]. The balance in the immune response of the host is strongly correlated with the clinical spectrum of the disease, which includes 5 distinct clinical forms, with 2 extremes, tuberculoid and lepromatous leprosy. Tuberculoid leprosy (TT) is characterized by resistance to bacilli proliferation due to a predominant Th1 response, which results in a strong cellular immune response. At the other extreme, lepromatous leprosy (LL) is characterized by the spread of bacilli due to a weak cellular immune response and a predominant Th2 response, which induces the production of antibodies [2].

Between these 2 extremes are intermediate or borderline (B) forms, which are considered unstable forms because they exhibit manifestations between TT and LL. The intermediate forms are borderline-tuberculoid (BT), borderline-borderline (BB), and borderline-lepromatous (BL), and these 3 forms show a gradual diminution in the cellular immune response and resistance to the bacilli [2]. Some authors [3,4] have suggested that these clinical forms can either oscillate or remain stable, and in the latter case, they are mutually incompatible. In B leprosy, so-called leprosy reactions occur. The type 1 reaction or reversal reaction (RR) affects mainly BL, BB, and BT patients and is associated with spontaneous acquisition of cellular immunity against $M$. leprae antigens $[5,6]$. The type 2 reaction or erythema nodosum leprosum (ENL) occurs in multibacillary patients (BL and LL) with low cellular immune responses and is related to the deposition of immune complexes in response to $M$. leprae antigens $[5,6]$. These type 1 and type 2 reactions affect $30 \%$ to $50 \%$ of patients, respectively, and cause great suffering and sequelae [5-7].

The influence of genetic factors on the ability of individuals to resist diseases, including leprosy, has long been studied $[8,9]$. The susceptibility phenotype of $M$. leprae infection is complex and is influenced by numerous factors in both the host and parasite as well as by environmental conditions [10].

The histocompatibility leukocyte antigen (HLA) complex, located on chromosome $6 \mathrm{p} 21$, is the most polymorphic genetic system in mammals [11]. The encoded proteins are involved in antigen presentation to T-cell receptors (TCRs), which triggers a specific immune response [12]. In leprosy, studies of the HLA complex have largely been focused on elucidating the mechanisms related to individual susceptibility/resistance and disease prognosis. Studies of HLA class I (HLA-A, HLA-B, and
HLA-C) have been conducted in various populations [13-18]. For HLA class II (HLA-DR and DQ), the most consistent findings are that HLA-DR2 (subtypes HLADRB1*15 and HLA-DRB1*16) and HLA-DQ1 (subtypes HLA-DQB1*05 and HLA-DQB1*06) are associated with the TT and LL clinical forms, respectively [19-27], and are also associated with leprosy per se [28-34]. To confirm these previous findings, 2 genome-wide linkage analyses was done and identified chromosome $6 \mathrm{p} 21$ as a major leprosy susceptibility locus in the HLA gene cluster $[35,36]$.

Based on these previous results, and because the involvement of HLA in borderline (B) leprosy and leprosy reactions have not been described, the aim of this study was to investigate the possible association of HLA class I and II alleles and haplotypes with B leprosy forms, including $\mathrm{BT}, \mathrm{BB}$, and $\mathrm{BL}$ and leprosy reactions in a sample population from São Paulo State, Brazil.

\section{Methods \\ Patients and controls}

This study included 202 patients diagnosed with leprosy classified as B type by a medical team in the Dr. Diltor V. A. Opromolla Department of Dermatology at Lauro de Souza Lima Institute (ILSL) in Bauru, São Paulo State, Southern Brazil. For the purpose of classification and inclusion in the study, we searched medical records to determine the details regarding clinical classification in addition to the complementary exams given at diagnosis, such as histopathology, Mitsuda reaction, and slit skin smear. The study patients were followed for 1 year to assess the presence and classification of leprosy reactions. Of the 202 patients, 143 (70.8\%) were men, and the ages of the patients ranged from 7 to 86 years, with a median age of 51 years. According to the clinical, immunological, baciloscopic, and histopathological indexes proposed by Ridley and Jopling [2], 88 patients were classified as having BB, 70 were classified as having BT, and 44 were classified as having BL. Ninety four patients (46.5\%) had reversal reactions, 10 patients $(4.95 \%)$ had an erythema nodosum leprosum (ENL) reactions at diagnosis and/or during the course of the disease, and 94 (46.5\%) had no leprosy reaction. For 4 of the 202 patients $(2.0 \%)$, no leprosy reactions were reported during the 1-year follow-up.

The control group consisted of 478 unrelated, healthy individuals of the same ethnicity from the same geographic region with no history of leprosy or other disease associated with HLA, who underwent HLA typing in the Immunogenetics Laboratory of ILSL. Of the 478 control individuals, 200 (41.8\%) were men, and the ages of the controls ranged from 20 to 68 years, with a median age of 37 years. 
This was a retrospective case-controlled study in which we used DNA samples obtained from patients and controls that were deposited in the DNA bank of the Immunogenetics Laboratory of ILSL. All subjects gave informed consent to participate in the study. The Ethics Committees of UNIFESP (1048/10) and ILSL (039/2010) approved this study.

\section{DNA extraction}

Peripheral venous blood samples were collected from patients into tubes containing anticoagulant EDTA, and DNA was extracted from buffy coats by using the saltingout technique [37]. DNA samples were stored in $-80^{\circ} \mathrm{C}$ until use.

\section{HLA class I and class II typing}

HLA class I (A*, B*, and $C^{*}$ loci) and class II (DRB1* and $\mathrm{DQB1}$ * loci) genotypes were determined at low resolution by using the Luminex 100 xMAP flow cytometry dual-laser system to quantify fluorescently labeled oligonucleotides attached to color-coded microbeads (One Lambda ${ }^{\circ}$, Canoga Park, CA, USA) according to the manufacturer's instructions. Briefly, the HLA region was amplified by polymerase chain reaction-sequence specific oligonucleotide (PCR-SSO) using a specific primer. The PCR product was denatured and hybridized to complementary DNA probes attached to fluorescently tagged microbeads. The biotinylated reaction product was detected through binding to streptavidin conjugated to R-phycoerythrin, which resulted in fluorescence emission. A flow analyzer, the LabScan ${ }^{\mathrm{TM}} 100$, was used to measure the fluorescence intensity of each microsphere. The data were analyzed with HLA Fusion software (One Lambda ${ }^{\oplus}$, Canoga Park, CA, USA).

\section{Statistical analysis}

Allele frequencies were determined by direct counting. The distribution of haplotype frequencies were estimated using the Expectation Maximization (EM) algorithm. Hardy-Weinberg equilibrium was tested to confirm the distribution of allele frequency. Both tests were performed by using Arlequin software, version 3.0 [38].

Case-controlled analyses of HLA alleles and B clinical forms (BB, BT, and $\mathrm{BL}$ ) were performed using the chisquare test or Fisher's exact test with Graph Pad (http:// www.graphpad.com/quickcalcs/contingency1.cfm). P values less than or equal to 0.05 were considered statistically significant. Bonferroni correction was applied when the $p$ values were significant (by multiplying the $p$ values by the number of HLA alleles being tested), and pc values less than or equal to 0.05 were considered significant. Odds ratios were calculated with a $95 \%$ confidence interval $(95 \% \mathrm{CI})$ using SISA when the $\mathrm{p}$ values were significant.

\section{Results}

The possible associations between HLA class I and class II alleles and B leprosy were assessed by comparing the frequencies of these alleles in patients with B leprosy to those in healthy controls and by comparing the frequencies in patients with different B clinical forms (BB, BT, and BL). Details of the analysis are shown in Additional file 1 and Additional file 2.

\section{B leprosy and healthy controls}

An increased frequency of HLA-B*07 was observed in B leprosy patients ( $18.81 \%$ vs. $12.78 \%$; $\mathrm{p}=0.043$, $\mathrm{OR}=1.58$, $95 \% \mathrm{CI}=1.02-2.5, \mathrm{pc}=1.37)$. HLA-B 53 (6.43\% vs. $2.93 \%$; $\mathrm{p}=0.050, \mathrm{OR}=2.28,95 \% \mathrm{CI}=1.05-4.94, \mathrm{pc}=1.60)$ and HLA-C*16 (10.4\% vs. 5.44\%; $\mathrm{p}=0.030, \mathrm{OR}=2.02,95 \%$ $\mathrm{CI}=1.10-3.67, \mathrm{pc}=0.48)$ were also more frequent in $\mathrm{B}$ leprosy patients than in healthy controls. A decreased frequencies of HLA-B*49 (0.99\% vs. 6.07\%; $\mathrm{p}=0.002$, $\mathrm{OR}=0.15,95 \% \mathrm{CI}=0.04-0.65, \mathrm{pc}=0.064), \mathrm{HLA}-\mathrm{B} * 50$ (1.98\% vs. $6.28 \% ; \mathrm{p}=0.019, \mathrm{OR}=0.30,95 \% \mathrm{CI}=0.10-0.87$, $\mathrm{pc}=0.608)$, HLA-C 05 (5.94\% vs. $14.02 \% ; \mathrm{p}=0.002, \mathrm{OR}=$ $0.38,95 \% \mathrm{CI}=0.20-0.73, \mathrm{pc}=0.032)$, and HLA-DRB1 07 (16.34\% vs. 26.77\%; $\mathrm{p}=0.003, \mathrm{OR}=0.53,95 \% \mathrm{CI}=0.3-0.8$, $\mathrm{pc}=0.039)$ were observed in the group of patients. After $\mathrm{p}$-value correction, the associations that remained significant were HLA-C*05 and HLA-DRB1*07, suggesting that these alleles provide protection against $B$ leprosy, whereas HLA-B*49 only showed a trend toward a protective effect. Table 1 shows the results of the HLA allele association analysis in B leprosy patients and the healthy controls.

\section{BB, BT, and BL leprosy and healthy controls}

Analysis of the HLA allele frequency showed an increased frequency of HLA-B*58 (11.36\% vs. 5.03\%; $\mathrm{p}=$ $0.028, \quad \mathrm{OR}=2.42,95 \% \mathrm{CI}=1.11-5.27, \mathrm{pc}=0.896)$ and HLA-C*12 (21.59\% vs. 13.39\%; $\mathrm{p}=0.050, \mathrm{OR}=1.78,95 \%$ $\mathrm{CI}=1.00-3.15, \mathrm{pc}=0.70)$ and a decreased frequency of HLA-B*49 (0.0\% vs. 6.07\%; $\mathrm{p}=0.014$, OR $=0.09,95 \% \mathrm{CI}=$ $0.005-1.42, \mathrm{pc}=0.448)$ and HLA-C ${ }^{*} 05(5.68 \%$ vs. $14.02 \%$, $\mathrm{p}=0.035, \mathrm{OR}=0.37,95 \% \mathrm{CI}=0.14-0.94, \mathrm{pc}=0.490)$ in patients with BB leprosy. After correction, these results did not remain significant. The results of the association analysis between BB leprosy and the healthy control group are shown in Table 2.

In the $\mathrm{BT}$ group, the analysis showed positive associations with HLA-A*33 (11.43\% vs. 5.23\%; $\mathrm{p}=0.056$, OR = $2.34,95 \% \mathrm{CI}=1.01-5.41, \mathrm{pc}=1.12), \mathrm{HLA}-\mathrm{B} * 53(8.57 \%$ vs. $2.93 \% ; \mathrm{p}=0.031, \mathrm{OR}=3.11,95 \% \mathrm{CI}=1.15-8.37, \mathrm{pc}=$ $0.992)$, HLA-C 16 (12.86\% vs. 5.44\%; $\mathrm{p}=0.031, \mathrm{OR}=2.56$, $95 \% \mathrm{CI}=1.15-5.73, \quad \mathrm{pc}=0.434)$, and HLA-DRB1*03 (28.57\% vs. $17.78 \%$; $\mathrm{p}=0.049, \mathrm{OR}=1.85,95 \% \mathrm{CI}=1.05-$ $3.27, \mathrm{pc}=0.637)$ and negative associations with HLA-B*40 (2.86\% vs. $10.46 \% ; \mathrm{p}=0.047, \mathrm{OR}=0.25,95 \% \mathrm{CI}=0.06-$ $1.06, \mathrm{pc}=1.50)$, HLA-B $* 9$ (0.0\% vs. $6.07 \% ; \mathrm{p}=0.039$, 
Table 1 HLA alleles showing statistically significant differences in frequency between B leprosy patients and healthy controls

\begin{tabular}{|c|c|c|c|c|c|c|c|c|c|}
\hline \multirow[t]{2}{*}{ B leprosy } & \multirow[t]{2}{*}{ HLA allele } & \multicolumn{2}{|c|}{ Patients $(\mathrm{N}=202)$} & \multicolumn{2}{|c|}{ Controls $(\mathrm{N}=478)$} & \multirow[t]{2}{*}{$p$} & \multirow[t]{2}{*}{ pc } & \multirow[t]{2}{*}{ OR } & \multirow[t]{2}{*}{ IC } \\
\hline & & $\mathrm{N}$ & $\%$ & $\mathrm{n}$ & $\%$ & & & & \\
\hline & $B * 07$ & 38 & 18.81 & 61 & 12.78 & 0.043 & 1.37 & 1.58 & $1.02-2.50$ \\
\hline & $B * 49$ & 2 & 0.99 & 29 & 6.07 & 0.002 & 0.064 & 0.15 & $0.04-0.65$ \\
\hline & $B * 50$ & 4 & 1.98 & 30 & 6.28 & 0.019 & 0.608 & 0.30 & $0.10-0.87$ \\
\hline & $B * 53$ & 13 & 6.43 & 14 & 2.93 & 0.050 & 1.60 & 2.28 & $1.05-4.94$ \\
\hline & $C * 05$ & 12 & 5.94 & 67 & 14.02 & 0.002 & 0.032 & 0.38 & $0.20-0.73$ \\
\hline & $C^{*} 16$ & 21 & 10.4 & 26 & 5.44 & 0.030 & 0.48 & 2.02 & $1.10-3.67$ \\
\hline & DRB $1 * 07$ & 33 & 16.34 & 128 & 26.77 & 0.003 & 0.039 & 0.53 & $0.30-0.80$ \\
\hline
\end{tabular}

$\mathrm{N}$ : number of individuals, $\mathrm{n}$ : number of alleles $(2 \mathrm{n}), \%$ : allele frequency, $\mathrm{p}$ : Fisher's exact test ( $\leq 0.05), \mathrm{pc}$ : corrected $\mathrm{p}$ value, OR: odds ratio, Cl: confidence interval, boldface: significant association after Bonferroni's correction.

$\mathrm{OR}=0.11,95 \% \mathrm{CI}=0.006-1.79, \mathrm{pc}=1.24)$, and HLAC*05 (4.28\% vs. 14.02\%; $\mathrm{p}=0.020$, OR $=0.27,95 \% \mathrm{CI}=$ $0.08-0.89$, $\mathrm{pc}=0.28)$. These results did not remain significant after $\mathrm{p}$ value correction (Table 2 ).

HLA allele frequencies that differed significantly between $\mathrm{BL}$ patients and healthy controls are shown in Table 2. HLA-B*53 was more common in BL patients (9.09\% vs. $2.93 \% ; \mathrm{p}=0.056, \mathrm{OR}=3.31,95 \% \mathrm{CI}=1.04-$ 10.54, pc $=1.792)$, whereas HLA-DRB1*07 (11.36\% vs $26.77 \% ; \mathrm{p}=0.028, \mathrm{OR}=0.35,95 \% \mathrm{CI}=0.13-0.91, \mathrm{pc}=$ $0.364)$ and HLA-DQB1*02 (18.18\% vs. 39.53\%; $\mathrm{p}=$ $0.005,95 \% \mathrm{CI}=0.15-0.75, \mathrm{pc}=0.025)$ were more frequent in the controls. After p value correction, only the negative association between HLA-DQB $1 * 02$ and BL leprosy remained significant, which suggests that it may have a protective effect against BL leprosy.

\section{HLA alleles and leprosy reactions}

The frequency of the HLA alleles in patients with leprosy reactions was analyzed only in the group of patients who had reversal reactions because only a small number of patients had ENL. In this analysis, patients who had reversal reactions were compared to patients without leprosy reactions, and the results are shown in Table 3. HLA-B $^{*} 15$ (28.72\% vs. $12.76 \%$; $\mathrm{p}=0.011$, OR $=2.75,95 \%$ $\mathrm{CI}=1.30-5.85, \mathrm{pc}=0.352)$ was positively correlated with reversal reactions; however, this correlation did not remain significant after correction.

Table 2 HLA alleles with statistically significant differences in BB, BT, and BL patients and healthy controls

\begin{tabular}{|c|c|c|c|c|c|c|c|c|c|}
\hline \multirow[t]{2}{*}{ BB } & \multirow[t]{2}{*}{ HLA allele } & \multicolumn{2}{|c|}{ Patients $(\mathrm{N}=\mathbf{8 8}$ ) } & \multicolumn{2}{|c|}{ Controls $(\mathrm{N}=478)$} & \multirow[t]{2}{*}{ p } & \multirow[t]{2}{*}{ pc } & \multirow[t]{2}{*}{ OR } & \multirow[t]{2}{*}{ IC } \\
\hline & & $\mathbf{N}$ & $\%$ & $\mathbf{n}$ & $\%$ & & & & \\
\hline & $B * 49$ & 0 & 0.00 & 29 & 6.07 & 0.014 & 0.448 & 0.09 & $0.005-1.42$ \\
\hline & $B * 58$ & 10 & 11.36 & 24 & 5.03 & 0.028 & 0.896 & 2.42 & $1.11-5.27$ \\
\hline & $C^{*} 05$ & 5 & 5.68 & 67 & 14.02 & 0.035 & 0.49 & 0.37 & $0.14-0.94$ \\
\hline & $C^{*} 12$ & 19 & 21.59 & 64 & 13.39 & 0.050 & 0.70 & 1.78 & $1.00-3.15$ \\
\hline \multirow[t]{8}{*}{$\overline{B T}$} & & \multicolumn{2}{|c|}{ Patients $(\mathrm{N}=70)$} & \multicolumn{2}{|c|}{ Controls $(\mathrm{N}=478)$} & & & & \\
\hline & $A * 33$ & 8 & 11.43 & 25 & 5.23 & 0.056 & 1.12 & 2.34 & $1.01-5.41$ \\
\hline & $B * 40$ & 2 & 2.86 & 50 & 10.46 & 0.047 & 1.50 & 0.25 & $0.06-1.06$ \\
\hline & $B * 49$ & 0 & 0.00 & 29 & 6.07 & 0.039 & 1.24 & 0.11 & $0.006-1.79$ \\
\hline & $B * 53$ & 6 & 8.57 & 14 & 2.93 & 0.031 & 0.992 & 3.11 & $1.15-8.37$ \\
\hline & $C^{*} 05$ & 3 & 4.28 & 67 & 14.02 & 0.020 & 0.28 & 0.27 & $0.08-0.89$ \\
\hline & $C^{*} 16$ & 9 & 12.86 & 26 & 5.44 & 0.031 & 0.434 & 2.56 & $1.15-5.73$ \\
\hline & DRB1*03 & 20 & 28.57 & 85 & 17.78 & 0.049 & 0.637 & 1.85 & $1.05-3.27$ \\
\hline \multirow[t]{4}{*}{$\mathrm{BL}$} & & \multicolumn{2}{|c|}{ Patients $(\mathrm{N}=44)$} & \multicolumn{2}{|c|}{ Controls $(\mathrm{N}=478)$} & & & & \\
\hline & $B * 53$ & 4 & 9.09 & 14 & 2.93 & 0.056 & 1.792 & 3.31 & $1.04-10.54$ \\
\hline & DRB1*07 & 5 & 11.36 & 128 & 26.77 & 0.028 & 0.364 & 0.35 & $0.13-0.91$ \\
\hline & $\mathrm{DQB} 1 * 02$ & 8 & 18.18 & 189 & 39.53 & 0.005 & 0.025 & 0.34 & $0.15-0.75$ \\
\hline
\end{tabular}

$\mathrm{N}$ : number of individuals, $\mathrm{n}$ : number of alleles $(2 \mathrm{n}), \%$ : allele frequency, $\mathrm{p}$ : Fisher's exact test $(\mathrm{p} \leq 0.05)$, pc: corrected $\mathrm{p}$ value, OR: odds ratio, Cl: confidence interval, boldface: significant association after Bonferroni's correction. 
Table 3 HLA alleles with statistically significant differences in frequency between patients with reversal reactions and those with no reaction

\begin{tabular}{|c|c|c|c|c|c|c|c|c|}
\hline \multirow[t]{2}{*}{ HLA allele } & \multicolumn{2}{|c|}{ Reversal reaction $(\mathrm{N}=94)$} & \multicolumn{2}{|c|}{ No reaction $(\mathrm{N}=94)$} & \multirow[t]{2}{*}{$\mathrm{p}$} & \multirow[t]{2}{*}{ pc } & \multirow[t]{2}{*}{ OR } & \multirow[t]{2}{*}{ IC } \\
\hline & $\bar{n}$ & $\%$ & $\mathrm{n}$ & $\%$ & & & & \\
\hline$B * 15$ & 27 & 28.72 & 12 & 12.76 & 0.011 & 0.672 & 2.75 & $1.30-5.85$ \\
\hline
\end{tabular}

$\mathrm{N}$ : number of individuals, $n$ : number of alleles $(2 n), \%$ : allele frequency, $p$ : Fisher's exact test $(p \leq 0.05)$, pc: corrected $p$ value, OR: odds ratio, Cl: confidence interval.

\section{HLA haplotypes and B leprosy}

Using the computational model in Arlequin 3.0, we obtained the expected frequencies of the HLA haplotypes in patients with B leprosy and healthy controls. In the B leprosy patients, it was possible to estimate 287 different haplotypes, and in the controls, it was possible to estimate 660 haplotypes. Table 4 shows only the most frequent haplotypes in the leprosy patients (greater than $1 \%)$ compared to the corresponding haplotypes in the controls. Due to the small number of patients in the study, we only analyzed B leprosy. The frequency of haplotypes $A^{* 02-B * 07-C * 07-D R B 1 * 15-D Q B 1 * 06 ~ a n d ~ A * 02-~}$ $\mathrm{B}^{*} 40-\mathrm{C}^{*} 03-\mathrm{DRB} 1 * 13-\mathrm{DQB1}{ }^{*} 06$ in B leprosy patients differed significantly from that in the controls $(0.029703 \mathrm{vs}$. $0.010460, \mathrm{p}=0.015$ and 0.017327 vs. $0.001046, \mathrm{p}=0.0011$, respectively), suggesting an association between these haplotypes and susceptibility to this form of leprosy.

We performed a comparative analysis of the alleles that were previously reported to be associated with the polar forms of leprosy (HLA-DRB1*15, HLA-DRB1*16, and HLA-DRB1*03 for TT and HLA-DQB1*05 and HLA-DQB1*06 for LL) by direct counting. These alleles were also present in B leprosy patients. The results of the analysis are shown in Table 5 . When analyzed separately, only the HLA-DRB1*16/DQB1*05 haplotype showed a statistically significant association (0.0891 vs. 0.0439; $\mathrm{p}=0.030)$. Although HLA-DRB1*16/DQB1*06 was significant, it was only found in the controls $(0.0000$ vs. $0.0420 ; \mathrm{p}=0.029)$. When the analysis was extended to all possible haplotypes, this association was most significant, with a $\mathrm{p}$ value of 0.0055 .

Table 6 summarizes the major findings of our B leprosy susceptibility and protection HLA allele association analysis along with a comparison to data from previous studies of different populations.

\section{Discussion}

Studies on the involvement of the HLA complex in leprosy have consistently shown that this major histocompatibility region contains the major genes associated with susceptibility to the disease [39]. Many HLA class II molecules have been consistently found to be associated with different clinical phenotypes and disease per se. Studies of HLA class I initially did not consider the possibility that presentation by $\mathrm{T}-\mathrm{CD} 8+$ lymphocytes could be important in leprosy. However, the positive association between HLA class I and leprosy reflects the role of these cells in the production of IFN- $\gamma$ in response to $M$. leprae antigens [39].

Previous studies of different clinical forms of leprosy mainly included just the polar forms LL and TT. The consensus in the literature is that HLA-DR2 (subtypes HLA-DRB1*15 and HLA-DRB1*16) and HLA-DR3 are associated with the TT form [19-23,27,40] and HLADQB1*01 (subtypes HLA-DQB1*05 and HLA-DQB1*06) is associated with the LL form $[25,26]$. No previous studies included only the intermediate clinical forms of the disease (BT, BB, and BL). Therefore, the current study was proposed.

The results showed decreased frequencies of HLAC*05 and HLA-DRB1*07 in B leprosy patients when compared to the healthy control individuals, suggesting that they are associated with protection against B leprosy. Analysis of HLA-B*49 showed a pc value that was nearly significant, suggesting a possible protective association. HLA-B*49 was found to be significantly associated with protection against leprosy per se in a Turkish population [41].

In a Brazilian population, HLA-C ${ }^{*} 05$ is 1 of the 5 most frequent alleles at this locus (approximately $14.0 \%$ in our control group), and HLA-DRB1*07 is the most frequent

Table 4 The HLA haplotypes in 202 B leprosy patients with frequencies above $1 \%$ and the frequencies in 478 controls

\begin{tabular}{|c|c|c|c|}
\hline HLA haplotype & B leprosy Hf & Control Hf & $\mathrm{p}$ \\
\hline$A * 02-B * 07-C * 07-D R B 1 * 15-D Q B 1 * 06$ & 0.029703 & 0.010460 & 0.015 \\
\hline$A^{*} 01-B^{*} 08-C * 07-D R B 1 * 03-D Q B 1 * 02$ & 0.027228 & 0.018828 & 1.000 \\
\hline$A^{* 02-B * 40-C * 03-D R B 1 * 13-D Q B 1 * 06}$ & 0.017327 & 0.001046 & 0.0011 \\
\hline$A^{*} 03-B^{*} 14-C * 08-D R B 1 * 01-D Q B 1 * 05$ & 0.014851 & 0.006276 & 0.197 \\
\hline$A^{* 02-B * 15-C * 03-D R B 1 * 04-D Q B 1 * 03}$ & 0.014851 & 0.007101 & 1.000 \\
\hline$A^{*} 24-B^{*} 07-C * 07-D R B 1 * 15-D Q B 1 * 06$ & 0.012376 & 0.002092 & 0.369 \\
\hline$A^{*} 02-B^{*} 51-C * 15-D R B 1 * 13-D Q B 1 * 06$ & 0.012376 & 0.005230 & 0.317 \\
\hline
\end{tabular}

Hf: haplotype frequency, $p$ : Fisher's exact test $(p \leq 0.05)$, boldface: significant association. 
Table 5 The frequencies of HLA-DRB1*15, HLA-DRB1*16, HLA-DRB1*03, HLA-DQB1*05, and HLA-DQB1*06 in 202 patients with $B$ leprosy and 478 controls

\begin{tabular}{|c|c|c|c|c|c|}
\hline \multirow[t]{2}{*}{ Haplotype } & \multicolumn{2}{|c|}{ Patients $(N=202)$} & \multicolumn{2}{|c|}{ Controls $(\mathrm{N}=478)$} & \multirow[t]{2}{*}{$\mathbf{p}$} \\
\hline & $\mathbf{N}$ & $\mathrm{AF}$ & $\mathbf{n}$ & $\mathrm{AF}$ & \\
\hline DRB1*15/DQB1*05 (\#) & 3 & 0.0148 & 3 & 0.0063 & 0.369 \\
\hline DRB1*15/DQB1*06 & 46 & 0.2277 & 82 & 0.1715 & 0.106 \\
\hline DRB1*16/DQB1*05 & 18 & 0.0891 & 21 & 0.0439 & 0.030 \\
\hline DRB1*16/DQB1*06 (\#) & 0 & 0.0000 & 2 & 0.0420 & 0.029 \\
\hline DRB1*03/DQB1*05 (\#) & 0 & 0.0000 & 0 & 0.0000 & 1.000 \\
\hline DRB1*03/DQB1*06 (\#) & 0 & 0.0000 & 1 & 0.0021 & 1,000 \\
\hline Total & 67 & 0.3317 & 109 & 22.80 & 0.0055 \\
\hline Others alleles & 135 & 0.6683 & 369 & 77.19 & \\
\hline
\end{tabular}

$\mathrm{N}$ : number of individuals, $\mathrm{n}$ : number of alleles $(2 \mathrm{n})$, AF: allele frequency, $\mathrm{p}$ : Fisher's exact test ( $\mathrm{p} \leq 0.05)$, (\#) haplotypes that are not in linkage disequilibrium, boldface: significant association.

(26.77\% in our control group) [42]. In B leprosy patients, we observed decreased frequencies for these 2 alleles (5.94\% for HLA-C*05 and $16.34 \%$ for HLA-DRB1*07). The protective effect of HLA-C"05 against in leprosy per se was recently described in a population in Rio de Janeiro, Brazil. However, in this study, the patients were not divided into groups according to their clinical forms; therefore, it was not possible to verify whether this allele was associated with B leprosy [43]. Rani et al. [24] reported a decreased frequency of HLA-DRB1*0701 in LL and BL patients compared to TT patients and healthy controls in a population from Northern India, and they assigned this allele a protective effect against multibacillary (MB) forms. HLA-DRB1*1501 and HLA-DQB1*0602 were associated with susceptibility in $\mathrm{MB}$ patients in Japan, and no allele was associated with protection in this population [34]. Silva et al. [32] reported that the HLADRB1*1601 allele was associated with susceptibility to B leprosy in a Brazilian population. In our study, no allele was associated with susceptibility.

Significant susceptibility and protective associations were observed in $\mathrm{BB}, \mathrm{BL}$, and $\mathrm{BT}$, although the corrected p was higher than the significance level (5\%). To confirm the associations in these clinical forms, the groups were compared 2 ways: BB, BL, and BT were compared with the healthy control group, and then each group (i.e., BB, $\mathrm{BL}$, or $\mathrm{BT}$ ) was compared to patients without the clinical form analyzed (see Additional file 2).

In the $\mathrm{BB}$ group, a protective association was observed for HLA-B*49 and HLA-C*05 when compared to the healthy controls. These same alleles were also found in $B$ leprosy. In both analyses (compared to healthy controls and patient controls), HLA-B*58 and HLA-C*12 were associated with susceptibility to the BB form. HLAC*12 was previously shown to be associated with susceptibility to leprosy per se in a population in Southeast

Table 6 Major findings in this study compared to previous data

\begin{tabular}{|c|c|c|c|c|c|c|c|c|}
\hline HLA association & B & BB & BT & BL & Reaction & Associated phenotype & Population & Reference \\
\hline$A * 33$ & - & - & Susc & - & - & Susc (L. per se) & Korea & 22 \\
\hline$B * 15$ & - & - & - & - & Susc & - & - & - \\
\hline$B * 58$ & - & Susc & - & - & - & - & - & - \\
\hline$B * 40$ & - & - & Prot & - & - & - & - & - \\
\hline$B * 49$ & Prot & Prot & Prot & - & - & Prot (L. per se) & Turkey & 35 \\
\hline$B * 53$ & - & - & Susc & Susc & - & - & - & - \\
\hline$C * 05$ & Prot & Prot & Prot & - & - & Prot (L. per se) & Brazil & 37 \\
\hline$C * 12$ & - & Susc & - & - & - & Susc (L. per se) & Brazil & 11 \\
\hline$C * 16$ & - & - & Susc & - & - & Prot (L. per se) & Brazil & 11 \\
\hline DRB1*03 & - & - & Susc & Prot & - & $\pi$ & Different populations & 16,34 \\
\hline DRB1*07 & Prot & - & - & Prot & - & Prot (MB) & India & 18 \\
\hline $\mathrm{DQB} 1 * 02$ & - & - & - & Prot & - & Prot (MB) & India and Argentina & 18,38 \\
\hline DQB1*04 & - & - & - & - & Susc & - & - & - \\
\hline
\end{tabular}


Brazil [17]; however, no study has shown an association between HLA-B*58 and leprosy. Although our statistical analyses did not support susceptibility $(p c \geq 0.05)$, the finding of HLA-B*58 in our patient group suggests that this allele is a specific marker for clinical BB leprosy in our region, as the frequency of this allele in the general population is approximately $5.0 \%$, whereas in BB patients, the frequency was $11.36 \%$ [42].

In BL patients, HLA-B*53 was associated with susceptibility when compared to the healthy controls; however, similar results were not observed when compared to the patient controls. The protective associations of HLADRB1*07 and HLA-DRB1*03 differed in the analyses with different control groups; HLA-DRB1*07 was significant when compared to the healthy controls, whereas HLA-DRB1*03 was significant when compared to the patient controls. Unlike the associations described above, HLA-DQB1*02 was associated with protection in BL patients when compared to both control groups, and a statistically significant association was maintained after Bonferroni correction.

Rani et al. [24] also reported a protective association for HLA-DQB1*02 as well as HLA-DRB1*07 in MB leprosy patients in India. Motta et al. [44] studied 89 leprosy patients (70 with $\mathrm{MB}$ and 19 with paucibacillary $[\mathrm{PB}]$ ) and 112 healthy controls in Argentina (province of Chaco), and confirmed HLA-DQB1*02 as a protective factor against the $\mathrm{MB}$ form. In this study, they also showed that HLA-DRB1*04 was associated with protection against the PB form. However, in our study, this association was not found in B leprosy patients, suggesting that HLA-DQB1*02 is specific to the BL form or MB patients.

In the BT group, a protective association was found for HLA-B*40 when compared to both control groups, whereas HLA-B*49 and HLA-C*05 were only found to be protective when compared to the healthy control group. HLA-B*49 and HLA-C*05 were also associated with protection against B leprosy. HLA-B*53 and HLAC*16 were associated with susceptibility only when compared to the healthy controls, whereas HLA-A*33 and HLA-DRB1*03 were associated with susceptibility when compared to both control groups. Kim et al. [28] showed that HLA-A*33 was shown associated with susceptibility to leprosy per se in Korea.

Studies $[22,40,45]$ of different populations have demonstrated an association between HLA-DRB1*03 and predisposition to TT. In our study, the association of this allele with BT suggests that it has an effect on susceptibility to this clinical form, as this same allele was found to be associated with protection against the BL form.

These results suggest that HLA-DRB1*03 is associated with polarization to the $B$ form and manifestation of this clinical form. Until now, this is a controversial point in the diagnosis of leprosy $[3,4]$. To better understand and confirm this result, the frequency of this allele in the polar forms of leprosy (LL and TT) should be determined, and these results should be replicated in other independent populations.

Due the small number of patients with ENL, they could not be studied. Therefore, only patients with reversal reactions were included, and a significant association with HLA-B"15 was found. Although this result lost significance after statistical correction, this finding must be considered, as the frequency of this allele differs considerably between patients with reversal reactions and non-reactional patients. In patients with reversal reactions, the frequency of HLA-B*15 was approximately $29.0 \%$, whereas in the non-reaction group, the frequency was $13.0 \%$.

In the literature, there are few studies describing the association between HLA and leprosy reactions. Ottenhoff found an association between HLA-DR3 and reactions in an Ethiopian population; however, this study involved a specific group of patients, Mitsuda-positive BT leprosy patients with reversal reactions. HLA-DR3 was shown to be involved in the acquisition of cellular immunity during the reactional state, but not in predisposition to this form of the disease [46]. In our study, HLA-DR3 was not associated with reactions. In addition, a negative association with BL was observed, which reinforces the hypothesis that HLA-DR3 is associated with BT leprosy and polarization in $\mathrm{B}$ leprosy.

The haplotype analysis showed that haplotypes $A^{*} 02$ B*07-C*07-DRB1*15-DQB1*06 and A*02-B*40-C*03DRB1*13-DQB1*06 were more frequent in B patients, and the difference between the frequencies in B leprosy patients and the controls was significant, suggesting a possible role in susceptibility to B leprosy. In Indian populations [15,16], MB leprosy was associated with

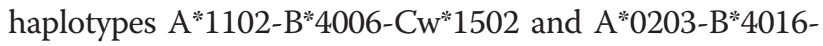
$\mathrm{CW}^{*} 0703$. Although the haplotypes are different, the $\mathrm{B} * 40$ allele found in these Indian populations was also detected in our population. However, it is not possible to say whether this allele genotype is the same as that observed in our population. In the Rio de Janeiro population, the haplotypes associated with susceptibility to leprosy per se were $A * 02-B * 35-C * 04, A * 02-B * 15-C * 03, A * 30-B * 42-C * 17$, $A * 03-B * 35-C * 04, A^{*} 26-B * 38-C * 12$, and $A * 24-B * 15-C * 03$, which differ from those found in our population [43].

Interestingly, the class II alleles present in both haplotypes found in our population, were previously shown to be associated with the clinical forms TT (DRB1*15) and LL (DQB1*06). This observation caused us to examine these class II alleles in B patients in greater detail. When analyzed independently, the results showed that haplotype HLA-DRB1*16/DQB1*05 was associated with susceptibility. 
Analysis of all possible haplotypes together (DRB1*15/ DQB1*05, DRB1*15/DQB1*06, DRB1*16/DQB1*05, DRB1*16/DQB1*06, DRB1*03/DQB1*05, and DRB1*03/ DQB1*06) showed a greater association with susceptibility. Thus, we hypothesized that the presence of alleles associated with the polar clinical forms LL and TT may induce the manifestation of $\mathrm{B}$ leprosy by triggering the intermediate immune response that is characteristic of this form of the disease.

\section{Conclusions}

The results of the present study showed the involvement of HLA class I and class II alleles in B leprosy and reversal reaction episodes and suggested a role for HLA molecules in polarization in this group of patients. Our findings provide a greater understanding of the immune responses exhibited by patients with B leprosy. In the future, similar studies of different populations are needed to confirm these findings.

\section{Additional files}

Additional file 1: $1.1 \mathrm{HLA}-\mathrm{A}^{*}, \mathrm{~B}^{*}, \mathrm{C}^{*}, \mathrm{DRB} 1^{*}$ and DQB1* alleles frequencies in 202 patients with $B$ leprosy and 478 healthy control. 1.2. $\mathrm{HLA}-\mathrm{A}^{*}, \mathrm{~B}^{*}, \mathrm{C}^{*}, \mathrm{DRB} 1^{*}$ and $\mathrm{DQB} 1^{*}$ alleles frequencies in $88 \mathrm{BB}$ leprosy and 478 healthy controls. 1.3. HLA-A*, $B^{*}, C^{*}, D R B 1^{*}$ and $D Q B 1^{*}$ alleles frequencies in $70 \mathrm{BT}$ leprosy and 478 healthy controls. 1.4. HLA-A*, $B^{*}, C^{*}$, $\mathrm{DRB}^{*}$ and $\mathrm{DQB1}{ }^{*}$ alleles frequencies in $44 \mathrm{BL}$ leprosy and 478 healthy controls. 1.5. HLA-A*, $B^{*}, C^{*}, D R B 1^{*}$ and $\mathrm{DQB} 1^{*}$ alleles frequencies in 94 leprosy patients with reversal reaction and 94 no reaction leprosy.

Additional file 2: 2.1 HLA-A*, B*, C*, DRB1* and DQB1* alleles frequencies in $70 \mathrm{BT}$ leprosy and $132 \mathrm{BB}$ and $\mathrm{BL}$ leprosy patients controls. 2.2. $\mathrm{HLA}-\mathrm{A}^{*}, \mathrm{~B}^{*}, \mathrm{C}^{*}, \mathrm{DRB} 1^{*}$ and $\mathrm{DQB} 1^{*}$ alleles frequencies in 88 $\mathrm{BB}$ leprosy and $114 \mathrm{BT}$ and $\mathrm{BL}$ leprosy patients controls. 2.3. HLA-A*, $\mathrm{B}^{*}$, $C^{*}, \mathrm{DRB} 1^{*}$ and $\mathrm{DQB1}{ }^{*}$ alleles frequencies in $44 \mathrm{BL}$ leprosy and $158 \mathrm{BT}$ and BB leprosy patients controls.

\section{Abbreviations}

M. leprae: Mycobacterium leprae; HLA: Human leukocyte antigen; TCR: T-cell receptor; TT: Tuberculoid leprosy; LL: Lepromatous leprosy; B: Borderline leprosy; BT: Borderline-tuberculoid; BB: Borderline-borderline; BL: Borderlinelepromatous; ILSL: Lauro de Souza Lima Institute; PCR-SSO: Polymerase chain reaction-sequence specific oligonucleotide; EM: Expectation maximization; MB: Multibacillary leprosy; PB: Paucibacillary leprosy.

\section{Competing interests}

The authors declare that they have no competing interests.

\section{Authors' contributions}

FCSS designed the study, conducted the molecular genetic studies and the statistical analyses, and wrote the manuscript. EVCM participated in the study design and in discussions about the study. MESN participated in the laboratory diagnosis of leprosy. SU selected the patients to participate in this study. JT participated in the study design and in discussions about the study, coordinated the study, and helped draft the manuscript. All authors read and approved the final manuscript.

\section{Acknowledgments}

This research was supported by Fundação Paulista Contra a Hanseníase (São Paulo/Brazil) and CAPES (Brazilian Ministry of Science and Technology).

\section{Author details}

${ }^{1}$ Immunogenetics Laboratory, Instituto Lauro de Souza Lima, Rod. Cte João Ribeiro de Barros, km 225/26, Bauru, SP CEP: 17039-800, Brazil. ${ }^{2}$ Immunology Laboratory, Instituto Lauro de Souza Lima, Rod. Cte João Ribeiro de Barros, km 225/26, Bauru, SP CEP: 17039-800, Brazil. ³Department of Education and Research, Instituto Lauro de Souza Lima, Rod. Cte João Ribeiro de Barros, km 225/26, Bauru, SP CEP: 17039-800, Brazil. "Department of Dermatology, Federal University of São Paulo, UNIFESP, Av. Borges Lagoa, 598, São Paulo, SP CEP: 04038-000, Brazil.

Received: 17 March 2014 Accepted: 12 January 2015

Published online: 21 January 2015

\section{References}

1. Rees RJW. The microbiology of leprosy. In: Hastings RC, editor. Leprosy 4th ed. Edinburg: Churchil Livingstone; 1994. p. 49-83.

2. Ridley DS, Jopling WH. Classification of leprosy according to immunity. A five-group system. Int J Lepr Other Mycobact Dis. 1966;34:255-73.

3. Opromolla DVA, Fleury RN. Formas clínicas de la lepra. Cidade do México: Anais Congresso Internacional de la Lepra; 1978.

4. Pereira Júnior AC, Gurfinkel AC. Positioning of borderline and indetermined groups in the hanseniasis classification. Hansen Int. 1981;6:63-70.

5. Scollard DM, Adams LB, Gillis TP, Krahenbuhl JL, Truman RW, Williams DL. The continuing challenges of leprosy. Clin Microbiol Rev. 2006;19:338-81.

6. Kumar B, Dogra S, Kaur I. Epidemiological characteristics of leprosy reactions: 15 years experience from north India. Int J Lepr Other Mycobact Dis. 2004;72:125-33.

7. Opromolla DVA. Manifestações Clínicas e Reações. In: Opromolla DVA, editor. Noções de Hansenologia. 2nd ed. Brasília: Centro de Estudos Dr. Reynaldo Quagliato; 2000. p. 51-8.

8. Ottenhoff THM, Verreck FAW, Hoeve MA, van de Vosse E. Control of human host immunity to mycobacteria. Tuberculosis. 2005;85:53-64.

9. Fitness J, Tosh K, Hill AVS. Genetics of susceptibility to leprosy. Genes Immun. 2002;3:441-53.

10. Petzel-Erler ML. Genetics of the immune response and disease susceptibility. Cienc Cult. 1999;51:199-211.

11. Abbas AK, Linchtman AHL, Pillai S. Cellular and molecular immunology. 6th ed. Philadelphia: Sauders Elsevier; 2010.

12. Lagrange $P$, Abel L. Susceptibilité génétique à la lèpre chez l'homme. Acta Leprol. 1996;10:11-27.

13. Takata H, Sada M, Ozawa S, Sekiguchi S. HLA and mycobacterial infection: increased frequency of B8 in Japanese leprosy. Tissue Antigens. 1978;11:61-4.

14. Chan SH. HLA and skin disease in the Chinese. Ann Acad Med Singapore. 1983;12:3-5.

15. Shankarkumar U, Ghosh K, Badakere S, Mohanty D. Novel HLA Class I Alleles Associated with Indian Leprosy Patients. J Biomed Biotechnol. 2003;2003:208-11

16. Shankarkumar U. HLA associations in leprosy patients from Mumbai, India. Lepr Rev. 2004;75:79-85.

17. Franceschi DSA, Tsuneto LT, Mazini PS, Sacramento WS, Reis PG, Rudnick CCC, et al. Class-I human leukocyte alleles in leprosy patients from Southern Brazil. Rev Soc Bras Med Trop. 2011;44:616-20.

18. Alter A, Huong NT, Singh M, Orlova M, Van Thuc N, Katoch K, et al. Human leukocyte antigen class I region single-nucleotide polymorphisms are associated with leprosy susceptibility in Vietnam and India. J Infect Dis. 2011;203:1274-81.

19. Van Eden W, de Vries RR, Mehra NK, Vaidya MC, D'Amaro J, van Rood JJ. HLA segregation of tuberculoid leprosy: confirmation of the DR2 marker. J Infect Dis. 1980;141:693-701.

20. De Vries RR, Mehra NK, Vaidya MC, Gupte MD, Meera Khan P, Van Rood JJ. HLA-linked control of susceptibility to tuberculoid leprosy and association with HLA-DR types. Tissue Antigens. 1980;16:294-304.

21. Van Eden W, Mehra NK, Vaidya MC, D'Amaro J, Schreuder GM, van Rood JJ. HLA and sporadic tuberculoid leprosy: a population study in Maharashtra, India. Tissue Antigens. 1981;18:189-94.

22. Van Eden W, de Vries RR, D'Amaro J, Schreuder I, Leiker DL, van Rood JJ. HLA-DR-associated genetic control of the type of leprosy in a population from surinam. Hum Immunol. 1982;4:343-50. 
23. Visentainer JE, Tsuneto LT, Serra MF, Peixoto PR, Petzl-Erler ML. Association of leprosy with HLA-DR2 in a Southern Brazilian population. Braz J Med Biol Res. 1997;30:51-9.

24. Rani R, Fernandez-Vina MA, Zaheer SA, Beena KR, Stastny P. Study of HLA class II alleles by PCR oligotyping in leprosy patients from north India. Tissue Antigens. 1993:42:133-7.

25. Klatser PR, Janson AM, Thole JE, Buhrer S, Bos C, Soebono H, et al. Humoral and cellular immune reactivity to recombinant $\mathrm{M}$. leprae antigens in HLA-typed leprosy patients and healthy controls. Int J Lepr Other Mycobact Dis. 1997:65:178-89.

26. Gorodezky C, Alaez C, Munguía A, Cruz R, Vazquez A, Camacho A, et al. Molecular mechanisms of $\mathrm{MHC}$ linked susceptibility in leprosy: towards the development of synthetic vaccines. Tuberculosis. 2004;84:82-92.

27. Marcos EVC, de Souza FC, Ura S, Opromolla DVA. Study of the association of HLA antigens and ulcerated type 1 leprotic reaction. An Bras Dermatol. 2000;75:282-90.

28. Kim SJ, Choi IH, Dahlberg S, Nisperos B, Kim JD, Hansen JA. HLA and leprosy in Koreans. Tissue Antigens. 1987;29:146-53.

29. Joko S, Numaga J, Kawashima H, Namisato M, Maeda H. Human leukocyte antigens in forms of leprosy among Japanese patients. Int J Lepr Other Mycobact Dis. 2000;68:49-56.

30. Hegazy AA, Abdel-Hamid IA, Ahmed E-SF, Hammad SM, Hawas SA. Leprosy in a high-prevalence Egyptian village: epidemiology and risk factors. Int J Dermatol. 2002;41:681-6.

31. Vanderborght PR, Pacheco AG, Moraes ME, Antoni G, Romero M, Verville $\mathrm{A}$, et al. HLA-DRB1*04 and DRB1*10 are associated with resistance and susceptibility, respectively, in Brazilian and Vietnamese leprosy patients. Genes Immun. 2007:8:320-4.

32. Da Silva SA, Mazini PS, Reis PG, Sell AM, Tsuneto LT, Peixoto PR, et al. HLA-DR and HLA-DQ alleles in patients from the south of Brazil: markers for leprosy susceptibility and resistance. BMC Infect Dis. 2009;9:134.

33. Zhang F, Liu H, Chen S, Wang C, Zhu C, Zhang L, et al. Evidence for an association of HLA-DRB1*15 and DRB $1 * 09$ with leprosy and the impact of DRB $1{ }^{*} 09$ on disease onset in a Chinese Han population. BMC Med Genet. 2009;10:133.

34. Joko S, Numaga J, Masuda K, Namisato M, Maeda H. HLA class II alleles and leprosy (Hansen's disease) classified by WHO-MDT criteria. Nihon Rai Gakkai Zasshi. 1996;65:121-7.

35. Miller EN, Jamieson SE, Joberty C, Fakiola M, Hudson D, Peacock CS, et al. Genome-wide scans for leprosy and tuberculosis susceptibility genes in Brazilians. Genes Immun. 2004;5:63-7.

36. Zhang F-R, Huang W, Chen S-M, Sun L-D, Liu H, Li Y, et al. Genomewide association study of leprosy. N Engl J Med. 2009;361:2609-18.

37. Miller SA, Dykes DD, Polesky HF. A simple salting out procedure for extracting DNA from human nucleated cells. Nucleic Acids Res. 1988;16:1215.

38. Excoffier L, Laval G, Schneider S. Arlequin (version 3.0): an integrated software package for population genetics data analysis. Evol Bioinform Online. 2005;1:47-50

39. Blackwell JM, Jamieson SE, Burgner D. HLA and infectious diseases. Clin Microbiol Rev. 2009;22:370-85.

40. Gorodezky C, Flores J, Arevalo N, Castro LE, Silva A, Rodriguez O. Tuberculoid leprosy in Mexicans is associated with HLA-DR3. Lepr Rev. 1987;58:401-6.

41. Koçak M, Balci M, Pençe B, Kundakçi N. Associations between human leukocyte antigens and leprosy in the Turkish population. Clin Exp Dermatol. 2002;27:235-9.

42. Gonzalez-Galarza FF, Christmas S, Middleton D, Jones AR. Allele frequency net: a database and online repository for immune gene frequencies in worldwide populations. Nucleic Acids Res. 2011;39:D913-9.

43. Romero M. Estudo de Associação entre o Sistema HLA e a Hanseníase. MsD thesis. Instituto Oswaldo Cruz; 2010. p. 101

44. Motta PMF, Cech N, Fontan C, Giménez MF, Lodeiro N, Marinic K, et al. Role of HLA-DR and HLA-DQ alleles in multibacillary leprosy and paucibacillary leprosy in the province of Chaco (Argentina). Enferm Infecc Microbiol Clin. 2007;25:627-31.
45. Van Eden W, Gonzalez NM, de Vries RR, Convit J, van Rood JJ. HLA-linked control of predisposition to lepromatous leprosy. J Infect Dis. 1985;151:9-14.

46. Ottenhoff TM, Converse G, De Vries R. HLA Antigens and Neural Reversal Reaction in Ethiopian Boderline Tuberculoid Leprosy Patients. Int JLeprosy. 1987;55:261-6.

\section{Submit your next manuscript to BioMed Central and take full advantage of:}

- Convenient online submission

- Thorough peer review

- No space constraints or color figure charges

- Immediate publication on acceptance

- Inclusion in PubMed, CAS, Scopus and Google Scholar

- Research which is freely available for redistribution 